\author{
Abstracta Iranica \\ Abstracta Iranica Revue bibliographique pour le domaine irano-aryen \\ Volume 37-38-39 | 2018 \\ Comptes rendus des publications de 2014-2016
}

\title{
Michael Herles. „Einflüsse der achämenidischen Kultur in Oshakan (Armenien)?"
}

\section{Astrid Nunn}

\section{(2) OpenEdition}

1 Journals

\section{Édition électronique}

URL : http://journals.openedition.org/abstractairanica/45534

DOI : 10.4000/abstractairanica.45534

ISBN : 1961-960X

ISSN : 1961-960X

Éditeur :

CNRS (UMR 7528 Mondes iraniens et indiens), Éditions de l'IFRI

Référence électronique

Astrid Nunn, « Michael Herles. „Einflüsse der achämenidischen Kultur in Oshakan (Armenien)?" », Abstracta Iranica [En ligne], Volume 37-38-39 | 2018, document 50, mis en ligne le 30 décembre 2018, consulté le 26 septembre 2020. URL : http://journals.openedition.org/abstractairanica/45534 ; DOI : https://doi.org/10.4000/abstractairanica.45534

Ce document a été généré automatiquement le 26 septembre 2020

Tous droits réservés 


\title{
Michael Herles. „Einflüsse der achämenidischen Kultur in Oshakan (Armenien)?"“
}

\author{
Astrid Nunn
}

\section{RÉFÉRENCE}

Michael Herles. „Einflüsse der achämenidischen Kultur in Oshakan (Armenien)?“, MDOG 147, 2015, p. 107-128.

1 L'A. travaille depuis plusieurs années en Arménie, en particulier sur les sites de Didi Kond et Pokr Blur tous deux situés près de la ville de Oshakan, à $40 \mathrm{~km}$ au nord-ouest d'Erivan. L'Arménie est devenue achéménide au plus tard en 513 ou 512 av. J.-C. et correspondait à une partie de l'ancien Urartu. L'administration perse de cette province n'est pas entièrement connue, néanmoins l'influence perse est indubitablement présente dans la culture matérielle. Même si la datation de certains apadanas - à Erebuni ou Argishtihinili/Armavir - oscille encore entre la fin de l'époque urartéenne et le début de l'époque achéménide, d'autres vestiges architecturaux (bases de colonnes), céramique et bijoux indiquent que l'occupation de sites urartéens persista dans la région d'Oshakan après la fin de l'époque achéménide. 


\section{AUTEURS}

\section{ASTRID NUNN}

Université de Munich 